\title{
Transcriptomic Analysis of Brassinosteroid Biosynthesis and Signaling Pathway Genes in Healthy and Malformed Tissues of Mango Variety Amrapalli
}

\author{
Ashok Yadav and Usha Kalidindi* \\ Division of Fruits and Horticultural Technology, Indian Agricultural Research Institute, \\ New Delhi-110012, India \\ *Corresponding author
}

\section{A B S T R A C T}

In present era, breeding in mango crop are still done through conventional methods which is a serious drawback as it is laborious and time consuming. Mango malformation is a serious disease causing great losses to mango industry. It is difficult to control mango

\section{Keywords}

Mango, Mango malformation,

Brassinosteroid,

Biosynthesis,

Signaling,

Pathways.

Article Info

Accepted:

19 June 2017

Available Online:

10 July 2017 malformation disease through use of any chemicals. Brassinosteroids (BR) are known to have a wide range of functions to biotic and abiotic stresses. No reports are available relating BR level with mango malformation till date. In the present study we analyzed the brassinosteroid level in malformed and healthy buds at different growth stages through transcriptomic approach by using illumina pair-end sequencing. In the present study we observed the transcripts related to BR's, target gene of BR's, biosynthesis, signaling pathways and differentially expressed genes (DEGs). The results indicated that biosynthesis genes were more in malformed tissues (MB-1:5, MB-2:6 \& MB-3:7) compared to healthy tissues (HB-1: 5, \& HB-2: 5) whereas BR signaling genes were more in healthy tissues (HB-1:24, HB-2: 26) compared to malformed tissues (MB-1:21, MB2:20 \& MB-3: 21). The brassinosteroids signaling pathway genes in healthy tissues increased from bud to panicle formation stages. Differential Expression analysis indicated that BZR-1 a signaling gene was significantly up regulated in healthy panicle formation stage compared to all malformed bud developmental stages. Among the target genes of BR's signaling PIF, MYB-30 TF were higher in number in malformed buds compared to healthy buds at different growth stages. The results could serve as breeding targets for mango crop improvement.

\section{Introduction}

Mangifera indica L. $(2 \mathrm{n}=2 \mathrm{x}=40)$, a highly heterozygous tropical fruit of the world in Anacardiaceae family belongs to order Sapindales. It is commonly known as "King of Fruits" and is famous worldwide for its color, taste, flavor and aroma (Singh et al., 2016).India being a land of mangoes, more than thousands varieties are grown in different states, which contribute to 50 per cent of total mango production in world (Kostermans and Bompard, 1993). According to horticulturists and historians, mango originated in India (Singh et al., 2016), which later on spread to South-East Asia, Malaysia and Sumatra. Among the biotic stresses, mango malformation is most destructive, since it causes gross deformations in vegetative and floral tissues of mango (Ploetz, 
2001). It is a serious constraint to mango industry (Kumar et al., 2011) and 50-80 per cent fruit yield losses are reported every year (Kumar and Chakrabarti, 1997). The etiology of malformation has been a contentious issue, and a wide range of biotic and abiotic factors have been reported to cause the disease, including viruses, mites and nutritional deficiencies (Ploetz et al., 2002; Nailwal et al., 2006; Jouyban, 2012). Convincing evidence on the involvement of a fungus as the causal agent of malformation has been in the literature for decades (Singh and Dhillon, 1990; Usha et al., 1997; Steenkamp et al., 2000; Ploetz et al., 2002, Nailwal et al., 2006; Chakrabarti, 2011). However, based on Koch's postulate and detailed cytological examination of the infected tissues, it is now established that a fungus, Fusarium mangiferae induces the symptoms of mango malformation disease (Britz et al., 2002; Usha et al., 2009; Iqbal et al., 2010). In spite of several decades of incessant research since its recognition in 1891, the etiology of this disease has not been established. Several mango malformation disease management strategies such as use of different chemical pesticides, hormones, pruning diseased panicles etc. met with little or no success (Chakrabarti, 2011).

The plant hormones namely auxin, gibberellin, cytokinin, abscisic acid, ethylene, salicylic acid, jasmonic acid are small signaling molecules controlling various development process in plants (Quecini et al., 2007; Rigal and Ma, 2014), and play important roles in plant-pathogen interactions (Fu et al., 2011). Besides these, a new class of phytohormone, brassinosteroids (BR) isolated from pollen of Brassica napus was discovered. Till now, a total of 69 types have been found. These BR's belongs to a polyhydroxylated steroid hormones having active roles in stimulating the plant growth development with a wide range of functions such as response to environmental biotic and abiotic stresses namely salt and drought stress tolerance, photo-morphogenesis, thermotolerance, stomatal development, oxidative stress tolerance, cell death control, disease resistance, herbicide and pesticide tolerance (Vriet et al., 2012; Gruszka, 2013). Brassinosteroids at molecular level enhance metabolism of protein and nucleic acid and also affect gene expression pattern in plants (Khripach et al., 2000). The PGPM (plant growth promoting molecules) brassinosteroids are widely distributed in the plant kingdom from lower to higher plants. The high concentration BR's is mainly found in reproductive organs of the plant with lesser quantity in other vegetative parts of the plants. In plants the BR's are found in pollens (Pachthong et al., 2006), anthers (Watanabe et al., 2000), panicles (Schmidt et al., 1995), seeds, seedlings (Antonchick et al., 2005), shoots (Fukuta et al., 2004), leaves (Sondhi et al., 2008), galls (Ikeda et al., 1983), stems, cambial region (Kim et al., 1990), roots (Yokota et al., 2001), flower buds (Takatsuto 1994), flowers, bran (Abe et al., 1995) and grains (Yokota et al., (1994).

Among the plant hormones, ethylene, jasmonic acid, salicylic acid, are playing crucial roles in governing the plant defense (Kunkel and Brooks, 2002; Genger et al., 2008). Beside these, brassinosteroid also play important role in controlling different diseases especially bacterial (rice), fungal (barley, tomato) and viral disease (tomato, tobacco, cucumber). According to Choudhary et al., (2012) brassinosteroids are involved in complex molecular interaction network, which induce host defense responses upon pathogen attack. The change in the phytohormone biosynthesis and signaling pathways may result in resistance due to combined effect of multiple pathogens. It is necessary to understand the complexity of brassinosteroid and its interaction with other 
plant hormone homeostasis during plantpathogen interactions in malformation disease for developing the hormone-based breeding strategies. Manipulating hormone biosynthesis and signaling pathways result in enhanced resistance to a certain type of pathogens (Holeski et al., 2012).

However, no research findings regarding effect of BR's on malformation are available. Hence the present study was initiated to investigate the effect of BR's biosynthesis and signaling pathways, through transcriptome analysis of healthy and malformed tissues of mango variety Amrapali. This transcriptome approach will help to find the differentially expressed genes of BR's biosynthesis and signaling pathways in healthy and malformed tissues and will be useful to find its relation with mango malformation.

\section{Materials and Methods}

\section{Plant material}

Mango buds of Amrapalli variety were used to study the transcriptomic analysis of phytohormone biosynthesis and signaling genes. Total five samples ( 2 healthy and 3 malformed tissues) at different growth stages were collected from the experimental orchard, Division of Fruits and Horticulture Technology, Indian Agricultural Research Institute, New Delhi.

The five samples used for the study are as follows: Single swollen malformed bud stage I (MB-1), Multiple malformed bud stage 2 (MB-2), Multiple malformed bud stage 3 (MB-3), Healthy bud stage 1 (HB-1) and Healthy bud stage 2 (HB-2). Immediately after the sample collection the buds were frozen in liquid $\mathrm{N}_{2}$ and stored at $-80^{\circ} \mathrm{C}$ upto RNA extraction.
Isolation, qualitative and quantitative analysis of total RNA

Total RNA was isolated from healthy (HB-1 and HB-2) and malformed tissues (MB-1, MB-2 and MB-3) at different growth stages. For each of the five stages we collected three biological replicates and two technical replicates to prepare one pooled RNA sample. Total RNA was isolated by using Trizol method (Hongbao, et al., 2008).

The quality of the isolated RNA was checked on $1 \%$ denatured Agarose gel for the presence of $25 \mathrm{~S}$ and $18 \mathrm{~S}$ bands. Further, total RNA was quantified using Qubit fluorometer.

\section{Illumina NextSeq 2 x 150 PE (Pair End) library preparations}

Illumina deep sequencing platform was used to generate the sequencing data from healthy and malformed tissues of mango cvAmarpali. Illumina TruSeq stranded mRNA Library Preparation Kit was used to prepare the paired-end cDNA sequencing libraries as per its described protocol. Briefly, mRNA was enriched from total RNA followed by fragmentation. The means of the library fragment size distributions for MB-1, MB-2, MB-3, HB-1 and HB-2 stages are 504bp, 467bp, 481bp, 462bp and 480bp respectively. The libraries were sequenced using 2 X 150 PE chemistry on NextSeq-500 and 5 Gb data per sample was generated.

The fragmented mRNA was converted into first strand cDNA, followed by second-strand generation, A-tailing, adapter ligation and finally ended by index PCR amplification of adaptor-ligated library. Library quantification and qualification was performed using DNA High Sensitivity Assay Kit. Trimmomatic (V0.30) software was used to filter Illumina reads with a Phred quality score below 20; discarding the rest of the sequence and 
keeping only pairs where both reads were larger than $40 \mathrm{bp}$. The transcripts were assembled using Bridger with default parameters. The statistical elements of the assembly were calculated by in house perl scripts.

\section{De novo transcriptome assembly}

The next generation sequencing for MB-1, MB-2, MB-3, HB-1 and HB-2 samples were performed using 2x150PEchemistry on the Illumina NextSeq platform and approximately 5-6 GB data was generated per sample. Trimmomatic (V-0.30) software was used to filter Illumina reads with a Phred quality score below 20; discarding the rest of the sequence and keeping only pairs where both reads were larger than $40 \mathrm{bp}$ (Bolger et al., 2014). The transcripts were assembled using Bridger with default parameters. CD-Hit was run on the above mentioned Bridger (Chang et al., 2015) assembled transcripts to get the unigenes. All CDS were predicted from the unigenes using Trandecoder (http://transdecoder.sf.net) with default parameters. Subsequently, the predicted CDS were annotated using BLASTX against NCBI nr database.

\section{Functional annotation and pathway analysis}

The predicted CDS were subjected to similarity search against NCBI's nonredundant (nr) database using the BLASTx algorithm. GO sequence distributions helps in specifying all the annotated nodes comprising of GO functional groups.

The platform independent java implementation of the Blast2GO PRO software (Gotz et al., 2008) was used to retrieve associated gene ontology (GO) terms describing biological processes, molecular functions, and cellular components. CDS associated with similar functions are assigned to same GO functional group. To further differentiate the NCBI nucleotide sequences and assembled sequences at the protein level, COG classification was undertaken to analyse the NCBI sequences. The unigenes sequences were aligned to COG database to classify and predict possible functions. To identify the biological pathways in all samples, the detected CDS were mapped to reference canonical pathways in KEGG using KEGG automatic annotation server (KAAS) (Kanehisa and Goto, 2000).

\section{Differential gene expression analysis}

The DESeq package was used to detect significantly DE genes between control and treated samples. DEG analysis was carried out for commonly occurring CDS (based on common NR blast hit accession) among the control and infected samples. The genes were found to be differentially expressed with a log fold-change value $>+2$ for up-regulated genes and $\log$ fold-change value $<-2$ for downregulated genes (Fig. 1).

\section{Results and Discussion}

\section{Identification of brassinosteroid related coding sequences (CDS) and their functional annotation}

The transcripts related to brassinosteroid were identified in all five malformed and healthy tissues at different growth stages (MB-1, MB2, MB-3, HB-1 and HB-2) and their total number varied from 8 (MB-3) to 15 (MB-1). The number of CDS in MB-1, MB-2, MB-3, HB-1 and HB-2 are 15, 12, 5, 8 and 13 respectively (Table 1). The BLASTX was used against the NCBI NR database to get the coding sequences functionally annotated.

The summary of BlastX annotation results are shown in the supplementary table 1. The identified functional categories of coding sequences are brassinosteroid insensitive 1- 
associated receptor kinase 1-like protein, Brassinosteroid LRR- receptor kinase-like, brassinosteroid signaling positive regulator family protein and brassinosteroid-6-oxidase 2 .

\section{Expression profile of brassinosteroid biosynthesis pathways genes}

Brassinosteroids biosynthesis pathway genes (Figure 2) namely DWF-4, CYP-85A2, ROT3 , CPD and DET-4 were observed in three malformed and two healthy tissues during bud to panicle development stages (Table 2). During bud to panicle development stages, the total number of biosynthesis genes showed increasing pattern in malformed tissues whereas in healthy tissues it remained unchanged. The expression of all brassinosteroids biosynthesis pathway genes namely DWF-4, CYP-85A2, ROT-3, CPD and DET-1 were similar at bud stages of healthy and malformed tissue whereas at panicle development stages, CYP-85A2 and CPD showed higher level at MB-3 stage compared to HB-2 stage; while rest of the genes (DWF-4, ROT-3 and DET-1) expressed similarly in healthy and malformed tissues at different growth stages.

\section{Expression profile of brassinosteroid signaling pathways genes}

Brassinosteroids signaling pathway (Figure 3) genes namelyBRI-1, BAK-1, BKI-1, BSK, BIN-2, BZR-1/2, TCH-4 and CYCD-3 were found in the mango transcriptome of healthy and malformed tissues (Table 3). The total number of signaling genes were more in healthy tissues (HB-1:24, HB-2: 26) compared to malformed tissues (MB-1:21, MB-2:20 and MB-3: 21). The higher number of brassinosteroids signaling genes observed at healthy bud stage (HBS-1) are BRI-1, BSK, BZR-1/2, and TCH-4 whereas at single swollen malformed bud stage (MB-1), BIN-2 was higher and BKI-1 and CYCD-3 were having similar expression in $\mathrm{HB}-1$ and $\mathrm{MB}-1$ tissues. BSK, BIN-2 and CYCD-3 genes were more during HB-2 stage compared to MB-3 stages whereas BAK-1 was higher at MB-3 stage compared to HB-2 stage and rest of the genes namely BRI-1, BKI-1, BZR-1/2, and $\mathrm{TCH}-4$ were similar in expression in MB-3 and HB-2 growth stages.

\section{DEG's of brassinosteroid biosynthesis and signaling pathways}

In healthy and malformed tissues of mango cv. Amrapali, the expression level variations at different growth stages for brassinosteroid biosynthesis and signaling pathway genes was performed through differential gene expression analysis. For better understanding of brassinosteroid interaction with malformation, the six possible combinations (HB-1 vs $_{\text {MB- }} 1$, HB-1 $1_{\text {Vs }}$ MB-2, HB-1 $1_{\text {vs }}$ MB3 , HB-2 vsMB-1, HB-2 vsMB-2, HB-2 vsMB3 ) were studied (Table 4). We compared the DEGs between the samples within a specific stage of healthy and malformed tissue. The DEG's analysis revealed that out of all brassinosteroid biosynthesis and signaling pathway genes studied, only three genes (CPD: carboxypeptidase-D; CYCD-3: Cyclin Delta-3 (D-type cyclins) and BZR1: Brassinazole-Resistant1) were significantly expressed. The total number of upregulated genes for CPD, CYCD-3 and BZR1 were (4, 3 , and 3$)$; and down regulated genes were (12, 2 and 0$)$ respectively.

\section{Target genes of brassinosteroids signaling}

In the mango transcriptome data of healthy and malformed tissues, we observed 7 different types of target genes of BR's signaling. They were PIF (Phytochromeinteracting factor), REF-6 (Relative of ELF6), SBI-1 (Suppressor of BRI1), PP2A (protein phosphatase 2A), LCMT (leucine carboxylmethyl transferase), IWS-1 (Interacts with SPT6) and MYB30-TF (MYB30 transcription factors). The number of IWS-1 
gene was similar in all stages of healthy and malformed tissues; while REF-6 gene was absent in all stages except in MB-1. The target genes PIF, SBI, LCMT, and MYB30TF were higher in MB-1 when compared to healthy tissues were higher in healthy tissues compared to MB-1 growth stage. During panicle development stage, PIF, MYB30-TF were more in MB-3 compared to $\mathrm{HB}-2$; while SBI, PP2A and LCMT were higher in HB-2 compared to MB-3 (Fig. 4).

Table.1 Number of brassinosteroid transcripts identified in different stages of Healthy and malformed tissue

\begin{tabular}{|l|l|l|l|l|l|}
\hline $\begin{array}{l}\text { Functional Categories of coding } \\
\text { sequences }\end{array}$ & MB-1 & MB-2 & MB-3 & HB-1 & HB-2 \\
\hline $\begin{array}{l}\text { Brassinosteroid insensitive 1-associated } \\
\text { receptor kinase 1 -like protein }\end{array}$ & 10 & 7 & 1 & 3 & 8 \\
\hline $\begin{array}{l}\text { Brassinosteroid LRR- receptor kinase- } \\
\text { like }\end{array}$ & 1 & 2 & 1 & 1 & 1 \\
\hline $\begin{array}{l}\text { Brassinosteroid signaling positive } \\
\text { regulator family protein }\end{array}$ & 2 & 2 & 3 & 3 & 4 \\
\hline Brassinosteroid-6-oxidase 2 & 2 & 1 & 0 & 1 & 0 \\
\hline Total transcripts & 15 & 12 & 5 & 8 & 13 \\
\hline
\end{tabular}

Table.2 Expression of Brassinosteroids biosynthesis pathways gene in Healthy and malformed stages

\begin{tabular}{|l|l|l|l|l|l|}
\hline $\begin{array}{l}\text { Stages } \\
\text { Genes }\end{array}$ & MB-1 & MB-2 & MB-3 & HB-1 & HB-2 \\
\hline DWF-4 & 1 & 1 & 1 & 1 & 1 \\
\hline CYP-85A2 & 1 & 1 & 2 & 1 & 1 \\
\hline ROT-3 & 1 & 1 & 1 & 1 & 1 \\
\hline CPD & 1 & 1 & 2 & 1 & 1 \\
\hline DET-1 & 1 & 2 & 1 & 1 & 1 \\
\hline Total Gene & 5 & 6 & 7 & 5 & 5 \\
\hline
\end{tabular}

Table.3 Expression of Brassinosteroids signaling pathways gene in Healthy and malformed stages

\begin{tabular}{|l|l|l|l|l|l|}
\hline $\begin{array}{l}\text { Stages } \\
\text { Genes }\end{array}$ & MB-1 & MB-2 & MB-3 & HB-1 & HB-2 \\
\hline BRI-1 & 1 & 1 & 1 & 2 & 1 \\
\hline BAK-1 & 2 & 2 & 2 & 2 & - \\
\hline BKI-1 & 2 & 2 & 3 & 2 & 3 \\
\hline BSK & 7 & 6 & 7 & 8 & 9 \\
\hline BIN-2 & 2 & 2 & 2 & 1 & 4 \\
\hline BZR-1/2 & 2 & 2 & 2 & 3 & 2 \\
\hline TCH-4 & 1 & 1 & 1 & 2 & 1 \\
\hline CYCD-3 & 4 & 4 & 3 & 4 & 6 \\
\hline Total Gene & 21 & 20 & 21 & 24 & 26 \\
\hline
\end{tabular}


Table.4 Differentially expressed genes of brassinosteroid biosynthesis and signaling pathways in six possible combinations of healthy and malformed tissue

\begin{tabular}{|l|l|l|l|l|}
\hline Stages & Expression & CPD & CYCD-3 & BZR1 \\
\hline \multirow{3}{*}{ HB-1 vs MB-1 } & Up-Regulated & 0 & 0 & 0 \\
\cline { 2 - 5 } & Down-Regulated & 2 & 1 & 0 \\
\hline \multirow{3}{*}{ HB-1 vs MB-2 } & Up-Regulated & 1 & 0 & 0 \\
\cline { 2 - 5 } & Down-Regulated & 2 & 0 & 0 \\
\hline \multirow{2}{*}{ HB-1 vs MB-3 } & Up-Regulated & 1 & 0 & 0 \\
\cline { 2 - 5 } & Down-Regulated & 1 & 1 & 0 \\
\hline \multirow{3}{*}{ HB-2 vs MB-1 } & Up-Regulated & 0 & 1 & 1 \\
\cline { 2 - 5 } & Down-Regulated & 4 & 0 & 0 \\
\hline \multirow{3}{*}{ HB-2 vs MB-2 } & Up-Regulated & 2 & 1 & 1 \\
\cline { 2 - 5 } & Down-Regulated & 3 & 0 & 0 \\
\hline \multirow{2}{*}{ HB-2 vs MB-3 } & Up-Regulated & 0 & 1 & 1 \\
\cline { 2 - 5 } & Down-Regulated & 0 & 0 & 0 \\
\hline \multirow{2}{*}{ Total } & Up-Regulated & 4 & 3 & 3 \\
\cline { 2 - 5 } & Down-Regulated & 12 & 2 & 0 \\
\hline
\end{tabular}

CPD: carboxypeptidase-D; CYCD-3: Cyclin Delta-3 (D-type cyclins) and BZR1: Brassinazole-Resistant1

Fig.1 Flow chart indicating the transcriptomic analysis of BR's in Healthy and malformed tissue of mango cultivar Amrapalli

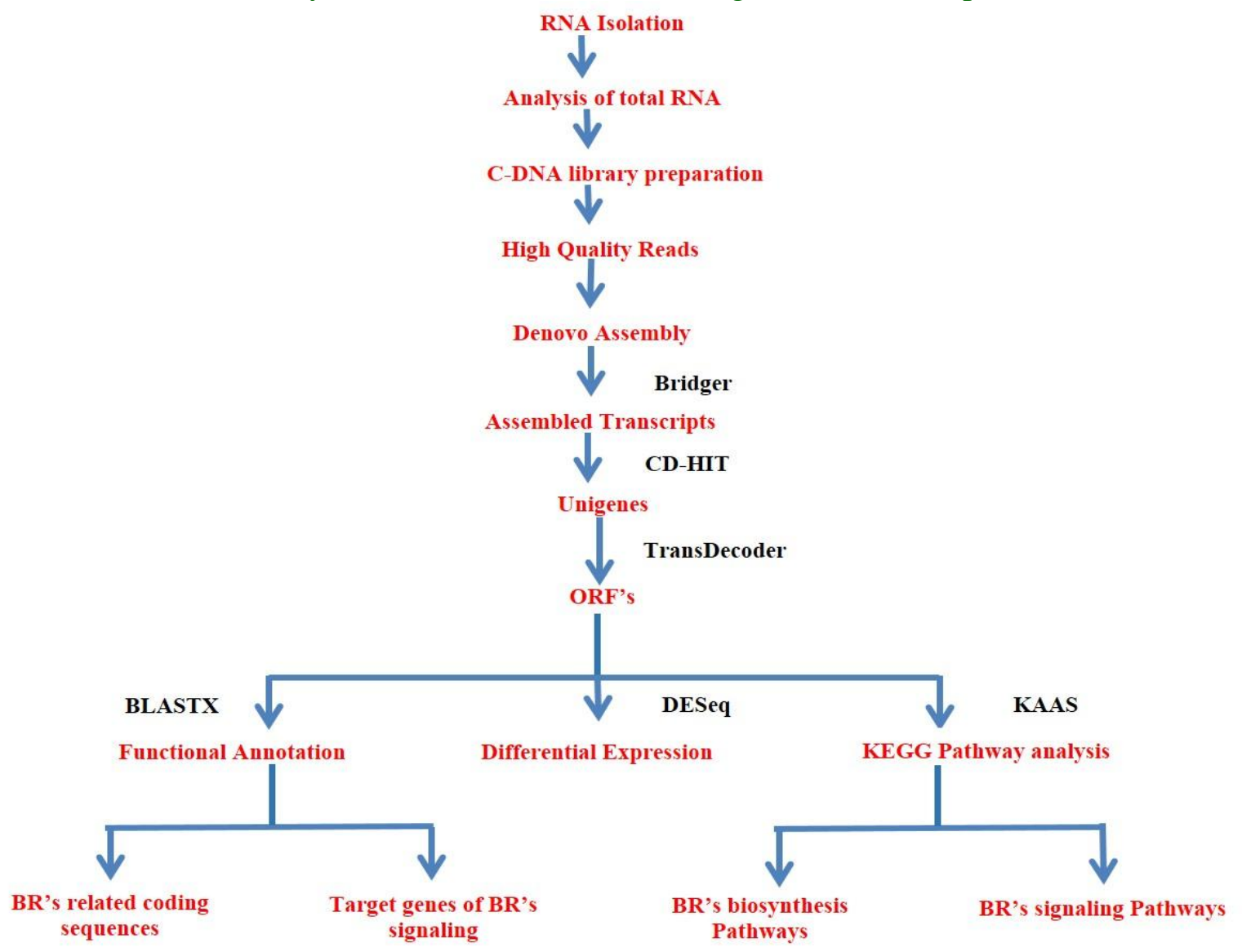


Fig.2 Proposed BR biosynthesis pathway genes in healthy and malformed tissue of mango cultivar Amrapalli which follow the Late C-6 Oxidation pathway (Chung and Choe, 2013)

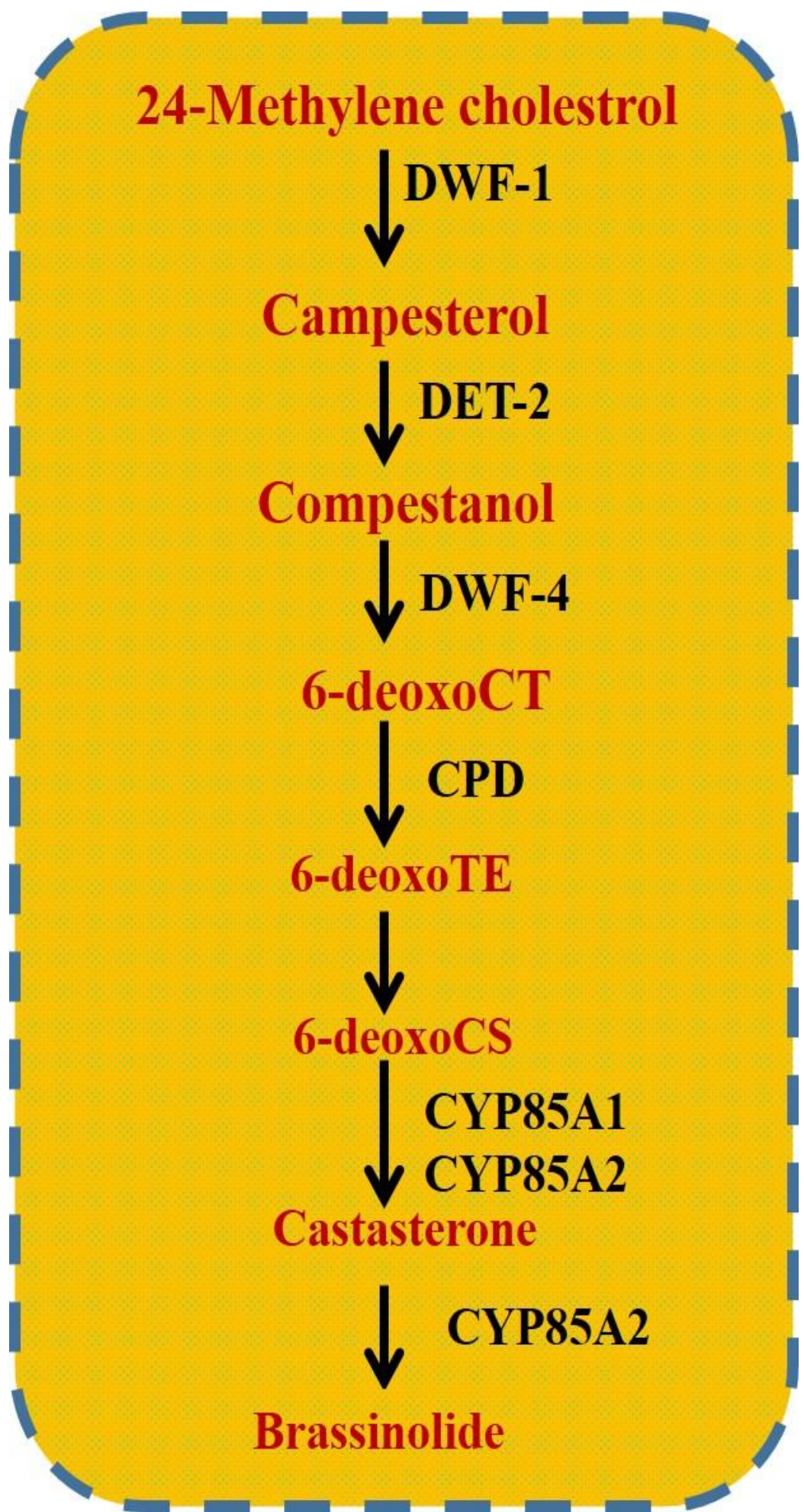

DWF-1: Dwarf-1; DWF-4: Dwarf-4; CYP-85A1: cytochrome-85A1 family; CYP-85A2: cytochrome-85A2 family; CPD: carboxypeptidase-D, DET-2: de-etiolated 2 homolog 
Fig.3 BR's signaling pathway genes in healthy and malformed tissue of

Mango cultivar Amrapalli

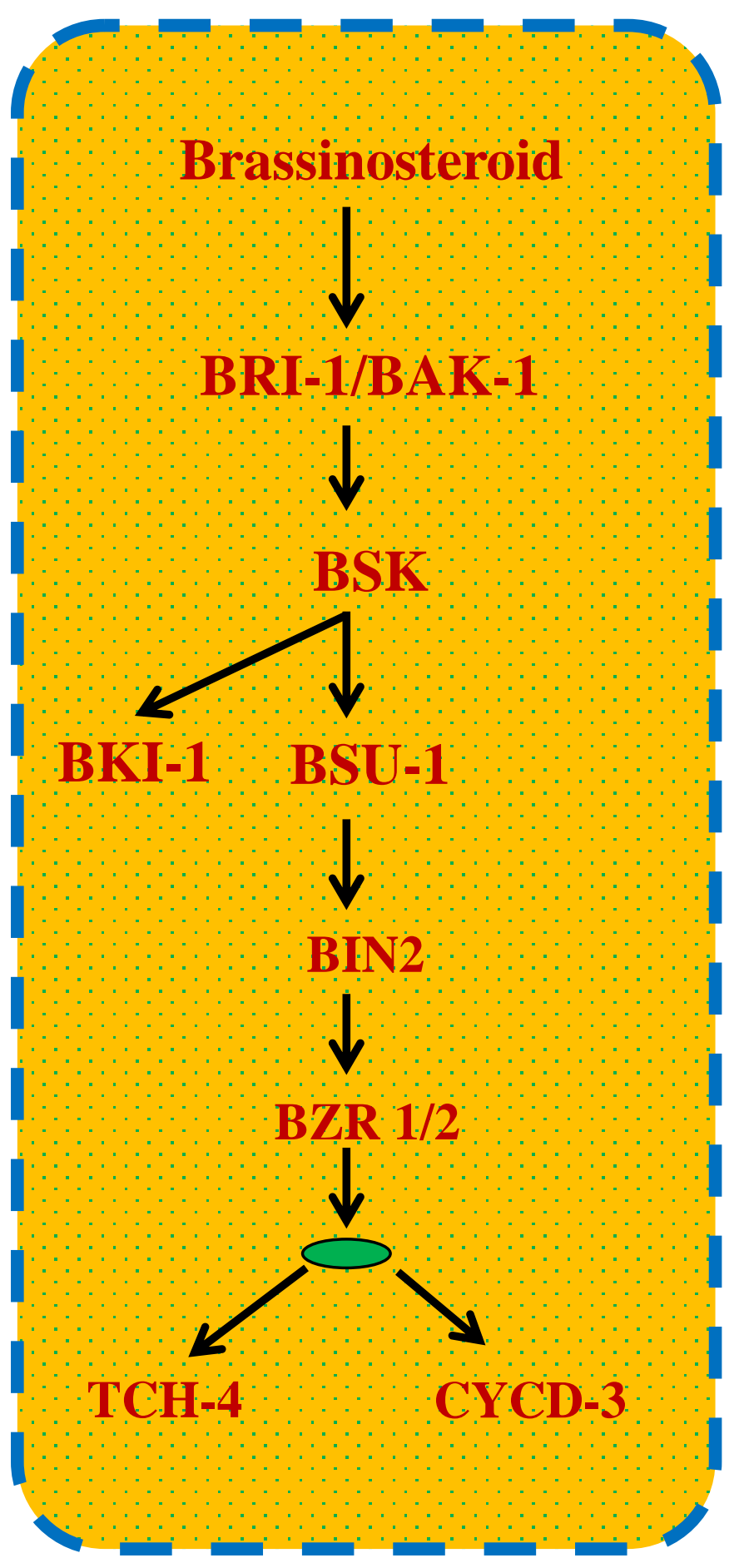

BRI-1: Brassinosteroid Insensitive1; BAK1: BRI1-Associated Receptor Kinase1; BKI1: BRI1 Kinase Inhibitor1, BSK1: Brassinosteroid Signaling Kinase1; BZR1: Brassinazole-Resistant1; BZR 2: Brassinazole-Resistant 2; TCH4: for touch; CYCD-3: Cyclin Delta-3 (D-type cyclins); BIN2: Brassinosteroid Insensitive 2, BSK: Brassinosteroid Signaling Kinase and BSU1:BRI1-Suppressor1 
Fig.4 Target of BR signaling genes in healthy and malformed tissues of Mango cultivar Amrapalli

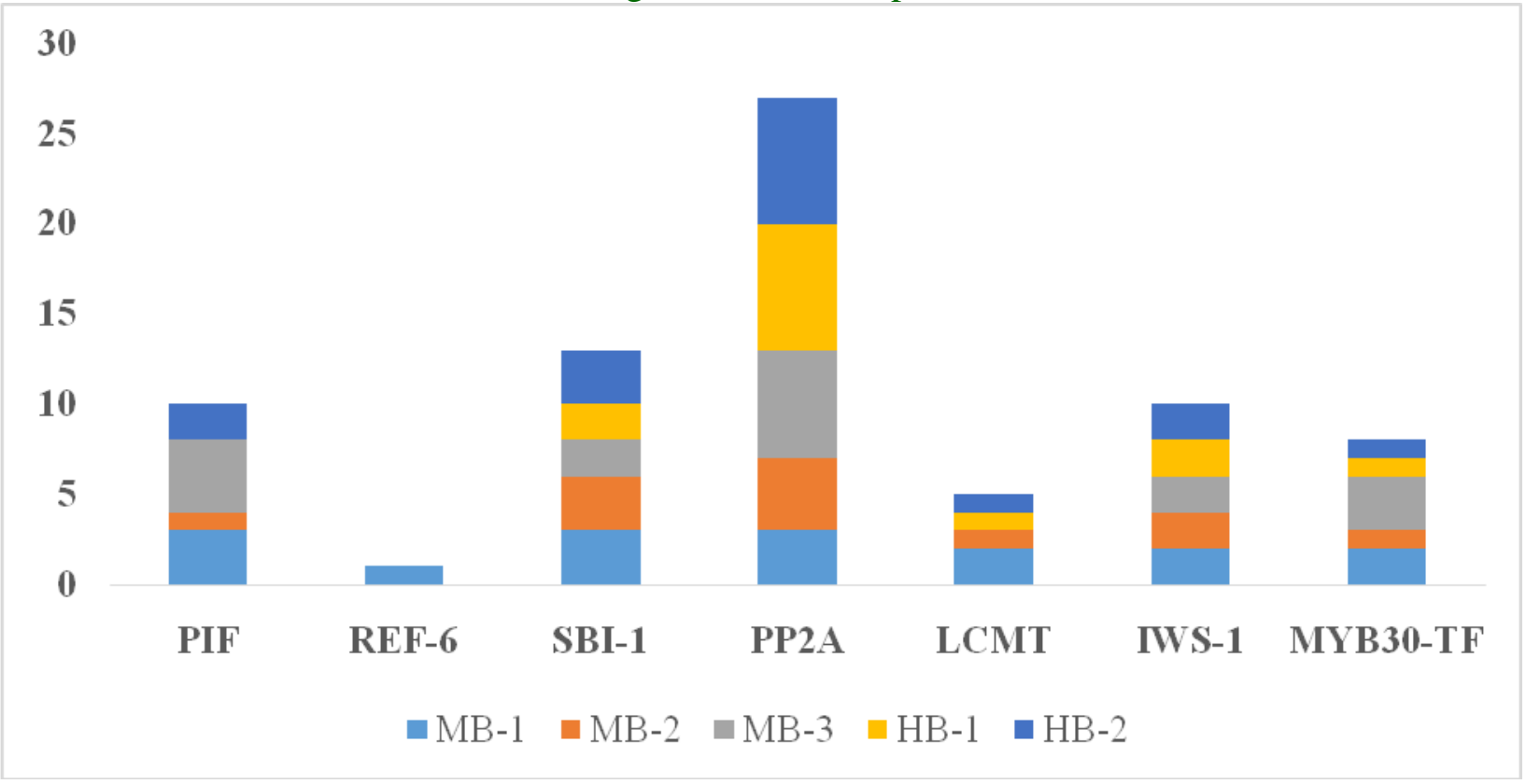

Brassinosteroids are the most important naturally occurring plant growth-promoting steroidal hormones which not only play a pivotal role in inducing the disease resistance or plant innate immunity but also regulates several growth and development processes like photo-morphogenesis, hormonal regulation, dwarfism, seed germination, change in the distribution pattern of stomata, flowering, senescence, pollen tube elongation, male sterility, xylem differentiation and root growth, confer tolerance/resistance to a broad range of biotic and abiotic stresses (thermal, salinity, oxidative, heavy metal stresses) in several plant species (Krishna, 2003; Kagale et al., 2007; Bajguzand Hayat, 2009; Divi and Krishna, 2010; Coll, et al., 2015).We observed that number of brassinosteroids synthesis genes in healthy (HB-1) and malformed buds (MB-1) were similar. In malformed tissues, the biosynthesis genes increased as the stage of malformation proceeds from MB-1 to MB-3; whereas in healthy tissues, from bud to panicle development stage, it remained unchanged. This probably could be due to the reason that in malformed panicles, the numbers of flowers are more and all flowers are male. Brassinosteroids are mainly synthesized in pollens resulting in more number of brassinosteroids biosynthesis genes in malformed tissues when compared to healthy tissues. Similar reports were also made in other crops by several workers (Yasuta et al., 1995; Zullo et al., 2002; Zhu et al., 2013).

Brassinosteroids signaling pathway genes in malformed tissue did not increase from bud to panicle development stages and are also less in number compared to healthy tissues. The brassinosteroids signaling pathway genes in healthy tissues increased from bud to panicle development stages. The BZR-1 is a positive regulator of $\mathrm{BR}$ signaling pathways (Lee $e t$ $a l ., 2015)$ and its fold change value is more in healthy tissues compared with malformed tissues and could be reason for observed more number of signaling genes in healthy tissues. The more number of signaling genes in healthy tissue might be the reason of resistance to malformation because it has been reported that the up-regulation of 
pathogen resistance is mainly due to $\mathrm{BR}$ signaling (Miyaji et al., 2014). We observed that the BR's signaling pathway is less active in malformed tissues compared to healthy tissues. Plant defective in BR's signaling results in dwarfism, leaves curling, and male sterility (Li et al., 2001).

BZR-1 gene was up-regulated in healthy tissues (HB-2) when compared to malformed tissues at all growth stages. The fold change value in $\mathrm{HB}-2_{\mathrm{VS}} \mathrm{MB}-1, \mathrm{HB}-2{ }_{\mathrm{vS}} \mathrm{MB}-2, \mathrm{HB}-2$ vsMB-3 were 45.36, 24.59 and 42.11. In our results we found that BZR-1 expression is low in malformed tissues due to which biosynthetic pathway gene of BR's are slightly more in malformed tissues. When BZR-1 expression is low, it leads to increase in the number of BR's biosynthesis genes that lead to formation of more BR's (He et al., 2005). Therefore BRs play crucial roles in bud growth and responses to Fusarium magiferae induced biotic stress in infected mango buds that lead to development of malformed panicles.

Brassinosteroids are a novel group of phytohormones having a broad spectrum of physiological activity and play crucial roles in plant growth and responses to stresses due to their growth promoting nature. BRs are having pleiotropic effect due to their diverse role in plant life cycle. We found that total numbers of biosynthesis pathway genes were more in mal formed tissues compared to healthy tissues; whereas the numbers of signaling genes were more in healthy tissues compared to malformed tissues. DEG's analysis showed that BZR-1 signaling gene was significantly up regulated in healthy panicle development stage compared to mal formed tissues at all growth stages. Among the target genes of BR's signaling PIF, MYB$30 \mathrm{TF}$ were higher in number in malformed tissues compared to healthy tissues. BR's role in regulating many different physiological processes appears to culminate in producing multiple beneficial effects in mango buds preventing infection by Fusarium mangiferae. BR-related genes could serve as breeding targets for mango crop improvement.

\section{References}

Abe, H., Takatsuto, S., Nakayama, M., and Yokota, T. 1995. 28-Homotyphasterol, a new natural brassinosteroid from rice (Oryza sativa L.) bran. Biosci. Biotech. Biochem, 59: 176-178.

Antonchick, A., Svatos, A., Schneider, B., Konstantinova, O.V., Zhabinskii, V.N., and Khripach, V.A. 2005. 2, 3Epoxybrassinosteroids are intermediates in the biosynthesis of castasterone in seedlings of Secalecereale. Phytochem, 66: $65-72$.

Bajguz, A., and Hayat, S. 2009. Effects of brassinosteroids on the plant responses to environmental stresses. Plant Physiol.Biochem, 47: 1-8. 3.

Britz, H., E. T., Steenkamp, T. A., Coutinho, B. D., Wingfield, W. F., Marasas, O. and Wingfield, M. J. 2002. Two new species of Fusarium section Liseola associated with mango malformation. Mycologia, 94(4):722-730.

Chakrabarti, D.K.2011. Mango malformation. Springer Science and Business Media.

Chang Z, Li G, Liu J, Zhang Y., Ashby C, Liu D, Cramer CL, and Huang X. 2015. Bridger: a new framework for de novo transcriptome assembly using RNA-seq data. Genome Biol., 16:30.

Chung, Y. and Choe, S. 2013. The regulation of brassinosteroid biosynthesis in Arabidopsis. Crit. Rev. Plant Sci., 32(6):396-410.

Choudhary, S.P., Yu, J.Q., YamaguchiShinozaki, K., Shinozaki, K. and Tran, L.S.P. 2012. Benefits of brassinosteroid crosstalk. Trends Plant Sci., 17(10): 594-605. 
Coll, Y., Coll, F., Amoros, A. and Pujol, M. 2015. Brassinosteroids roles and applications: an up-date. Biologia, 70(6):726-732.

Divi, U. K. and Krishna, P. Brassinosteroids confer stress tolerance. 2010. In: Hirt, H. Ed. Plant Stress Biology: from Genomics to System Biology. 119-135 (Wiley-VCH, 2010a).

Fukuta, N., Fujioka, S., Takatsuto, S., Yoshida, S., Fukuta, Y., and Nakayama, M. 2004. 'Rinrei', a brassinosteroiddeficient dwarf mutant of faba bean (Viciafaba). Physiol. Plant., 121: 506512.

Fu, J., Liu, H., Li, Y., Yu, H., Li, X., Xiao, J., and Wang, S. 2011. Manipulating broad spectrum disease resistance by suppressing pathogen-induced auxin accumulation in rice. Plant Physiol. 155:589-602.

Genger, R.K., Jurkowski, G.I., McDowell, J.M., Lu, H., Jung, H.W., Greenberg, J.T. and Bent, A.F.2008. Signaling pathways that regulate the enhanced disease resistance of Arabidopsis "defense, no death" mutants. Mol. Plant-Microbe Interact, 21(10):12851296.

Gotz S, Garcia-Gomez JM, Terol J, Williams TD, Nagaraj SH, Nueda MJ, Robles M, Talon M, Dopazo J, Conesa A. 2008.High-throughput functional annotation and data mining with the Blast2GO suite. Nucleic Acids Res., 36:3420-3435.

Gruszka, D.2013. The brassinosteroid signaling pathway-new key players and interconnections with other signaling networks crucial for plant development and stress tolerance. Int. $J$. Mol. Sci., 14(5): 8740-8774.

He, J.X., Gendron, J.M., Sun, Y., Gampala, S.S., Gendron, N., Sun, C.Q. and Wang, Z.Y. 2005. BZR1 is a transcriptional repressor with dual roles in brassinosteroid homeostasis and growth responses. Science, 307(5715):16341638.

Holeski, L. M., Jander, G., and Agrawal, A. A.2012. Transgenerational defense induction and epigenetic inheritance in plants. Trends Ecol. Evol. 27:618-626.

Ikeda, M., Takatsuto, S., Sassa, T., Ikekawa, N., and Nukina, M. 1983. Identification of brassinolide and its analogues in chestnut gall tissue. Agric. Biol. Chem., 47: 655-657.

Iqbal, Z., Pervez, M.A., Saleem, B.T., Ahmad, S., Dasti, A.A. and Saleem, A. 2010. Potential of Fusarium mangiferae as an etiological agent of mango malformation. Pakistan J. Bot., 42(1): $409-415$.

Jouyban, Z.2012. Ethylene biosynthesis. Tech. J.Engg. Appl. Sci., 1:107-110

Kanehisa M, and Goto, S.2000.KEGG: Kyoto Encyclopaedia of genes and genomes. Nucleic Acids Res., 28: 27-30.

Khripach, V., Zhabinskii, V. and de Groot, A. 2000. Twenty years of brassinosteroids: steroidal plant hormones warrant better crops for the XXI century. Ann. Bot., 86(3):441-447.

Kim, S.-K., Abe, H., Little, C.H.A., and Pharis, R.P. 1990. Identification of two brassinosteroids from the cambial region of scots pine (Pinus silvestris) by gas chromatography-mass spectrometry, after detection using a dwarf rice lamina inclination bioassay. Plant Physiol., 94: 1709-1713

Kostermans, A.J.G.H. and Bompard, J. M.1993.The Mangoes, their botany, nomenclature, horticulture and utilisation. Academic Press.

Kumar, R. and Chakrabarti, D.K.1997. Assesment of loss in yield of mango (Mangifera indica) caused by mango malformation. Indian J.Agr. Sci., 67(3).

Kumar, P., Misra, A.K., and Modi, D.R. 2011.Current status of mango 
malformation in India. Asian J. Plant Sci. 10:1.

Kunkel, B.N. and Brooks, D.M. 2002. Cross talk between signaling pathways in pathogen defense. Current opinion in plant biology, 5(4):325-331.

Krishna, P. 2003.Brassinosteroid-mediated stress responses. J. Plant Growth Regul. 22:289-297.

Kagale, S., Divi, U.K., Krochko, J.E., Keller, W.A., Krishna, P. 2007. Brassinosteroid confers tolerance in Arabidopsis thaliana and Brassica napus to a range of abiotic stresses. Planta, 225: 353364.

Lee, H.S., Kim, Y., Pham, G., Kim, J.W., Song, J.H., Lee, Y., Hwang, Y.S., Roux, S.J., Kim, S.H. 2015. Brassinazole resistant 1 (BZR1)-dependent brassinosteroid signalling pathway leads to ectopic activation of quiescent cell division and suppresses columella stem cell differentiation. J. Exp. Bot., 66 (15):4835-49.

Li，J., Nam，K.H., Vafeados，D. and Chory, J. 2001. BIN2, a new brassinosteroidinsensitive locus in Arabidopsis. Plant Physiol. 127:14-22.

Miyaji T, Yamagami A, Kume N, Sakuta M, Osada H, Asami T, Arimoto Y, Nakano T. 2014. Brassinosteroid-related transcription factor BIL1/BZR1 increases plant resistance to insect feeding. Biosci. Biotechnol. Biochem, 78(6):960-8.

Nailwal, T.K., Gomathi, K.A., Bains, G. Sand N.K., Shukla, A. and Pant, R.C. 2006. Mango (Mangifera indica L.) malformation: role of stress ethylene and cyanide. Physiol. Mol. Biol. Plants, 12(2):163.

Pachthong, C., Supyen, D., Buddhasukh, D. and Jatisatienr, A. 2006. Isolation and characterization of brassinolide and castasterone in the pollen of pumpkin. Chiang Mai Journal of
Science, 33(1):95-101.

Ploetz, R. C.2001. Malformation: A unique and important disease of mango, Mangifera indica L. In : B. A. Summerell, J. F. Leslie, D. Backhouse, W. L. Bryden and L. W. Burgess (Eds.), Fusarium: Paul E. Nelson memorial symposium, St. Paul, MN: The Amer. Phytopathol. Soc. Pp. 233-247.

Ploetz, R., Zheng, Q. I., Vazquez, A., and Abdel, S. M. A. 2002. Current status and impact of mango malformation in Egypt. Int. J. Pest Mangt.48: 279-285.

Quecini, V., Torres, G.A., Rosa Jr, V.E.D., Gimenes, M.A., Machado, J.B.D.M., Figueira, A.V.D.O., Benedito, V., Targon, M.L.P. and Cristofani-Yaly, M., 2007. In silico analysis of phytohormone metabolism and communication pathways in citrus transcriptome. Genet.Mol. Biol., 30(3):713-733.

Rigal, A. and Ma, Q., 2014. Unraveling plant hormone signaling through the use of small molecules. Front. Plant Sci., 5:373.

Schmidt, J., Himmelreich, U. and Adam, G.1995. Brassinosteroids, sterols and lup-20 (29)-en-2 $\alpha, 3 \beta, 28$-triol from Rheum rhabarbarum. Phytochem, 40(2):527531.

Hongbao, M., Young, J. and Shen, C. 2008. RNA, DNA and protein isolation using TRIzol reagent. Nat. Sci. 6:1545-0740.

Singh, N.K., Mahato A.K., Jayaswal, P. K., Singh, A., Singh, S., Singh, N., Rai V.,et al., 2016.Origin, Diversity and Genome Sequence of Mango (Mangifera indica L.) Indian. J. Hist. Sci. 51:355-368.

Sondhi, N., Bhardwaj, R., Kaur, S., Kumar, N., and Singh, B. 2008. Isolation of 24epibrassinolide from leaves of Aegle marmelos and evaluation of its antigenotoxicity employing Allium cepa 
chromosomal aberration assay. Plant Growth Regul, 54: 217-224.

Steenkamp, E.T., Britz, H., Coutinho, T.A., Wingfield, B.D., Marasas, W.F.O. and Wingfield, B. D.2000.Molecular characterization of Fusarium subglutinans associated with mango malformation. Mol. Plant Pathol. 1: 187-193.

Takatsuto, S. 1994. Brassinosteroids: distribution in plants, bioassays and microanalysis by gas chromatography mass spectrometry. J. Chromatogr. A, 658: 3-15.

Usha, K., Goswami, A. M., Sharma, H. C., Pande, P. C. and Singh, B. 1997. Scanning electron microscopic studies on floral malformation in mango. Scientia Hort. 71: 127-130.

Usha, K., Singh, B., Praseetha, P., Deepa, N., Agarwal, D. K., Agarwal, R. and Nagaraja, A. (2009). Antifungal activity of Datura stramonium, Calotropis gigantea and Azadirachta indica against Fusarium mangiferae and floral malformation in mango. European $\mathrm{J}$. Pl. Pathol. 124(4): 637-657.

Vriet, C., Russinova, E. and Reuzeau, C. 2012. Boosting crop yields with plant steroids. The Plant Cell, 24(3):842-857.

Watanabe, T., Yokota, T., Shibata, K., Nomura, T., Seto, H. and Takatsuto, S. 2000.Cryptolide, a new brassinolide catabolite with a 23-oxo group from
Japanese cedar pollen/anther and its synthesis. J. Chem. Res.-S: 18-19.

Yokota, T., Nakayama, M., Wakisaka, T., Schmidt, J., and Adam, G. 1994. 3Dehydroteasterone, a 3, 6diketobrassinosteroid as a possible biosynthetic intermediate of brassinolide from wheat grain. Biosci. Biotech. Biochem, 58: 1183-1185.

Yokota, T., Sato, T., Takeuchi, Y., Nomura, T., Uno, K., Watanabe, T., and Takatsuto, S. 2001. Roots and shoots of tomato produce 6-deoxo-28cathasterone, 6-deoxo-28nortyphasterol and 6-deoxo-28norcastasterone, possible precursors of 28-norcastasterone. Phytochem, 58: 233-238.

Yasuta, E., Terahata, T., Nakayama, M., Abe, H., Takatsuto, S., and Yokota, T.1995.Free and Conjugated Brassinosteroids in the Pollen and Anthers of Erythronium japonicum Decne. Biosci. Biotechnol. Biochem, 59 (11):2156-8.

Zullo, M.A.T. and Adam, G.2002. Brassinosteroid phytohormones: structure, bioactivity and applications. Braz. J. Plant Physiol., 14(3):143-181.

Zhu, J.Y., Sae-Seaw, J. and Wang, Z.Y.2013. Brassinosteroid Development, 140(8):1615-1620.

\section{How to cite this article:}

Ashok Yadav and Usha Kalidindi. 2017. Transcriptomic Analysis of Brassinosteroid Biosynthesis and Signaling Pathway Genes in Healthy and Malformed Tissues of Mango Variety Amrapalli. Int.J.Curr.Microbiol.App.Sci. 6(7): 1462-1475. doi: https://doi.org/10.20546/ijcmas.2017.607.175 